anerkannt haben. dass der einzige durchoreiftnde Unterschied z.m Zeit die Bildung des Diphtherietoxins sei. dass beispielsweise anch die M. Neisser sche Farbung uicht beweisend sein kơne. Es ditrfte jetzt. kein $Z$ weifel mehr darïber bestehen. was ieh schon vol vier Jahren ausgesprochen habe $)$. (lass es ausser den echten Iiphtheriebacilius nochl einen sehr verbreiteten Saprophyten gicbt. der sich von diesem durch nichts unterscheidet, als durch die Giftigkeit.

Es ist nun die Frage. kamn die Giftigkeit allein als ein durchgreifender Unterschied betrachtet werden? C. Fraenkel hat sich hierzu schon geäussert. er sagt: Die Virulenz hat sich nachgerade bei allen unseren Bacterien als eine so veränderliche Higrenschat erwiesen, diss sie zur Abgrenzung sonst iibereinstinmender Arten kaum benutzt werdem kann. Aber wir können beim Diphtheriebacillus selbst auch ohne Ilinweis anf das Verhalten anderer Bacterien nachweisen. dass die Giftigkeit mit aller Walırscheinlichkeit keinen durchgreifenden Unterschied argiebt. Dass wir giftige Diphtheriebacillen schon durch die $\Lambda$ rt des Nïllubodeus rasch ungiftig nachen können. ist hekaunt. aber ebenso soll es geglückt sein. dio Giftigkeit im ungekehrten Sinne zu beeinflussen. Roux und Yersin wollen schwachgiftige Bacillen vermittels gleichzeitiger Finspritzung von Streptocorcen so verstürkt laben. dass sie ganz d'n 'lypus der echtrin Loeffler schen stabehen annahmen und von diesem inch in Thierexperiment nicht zll unterscheiden waren.

Die interessanteste und wichtigste hierher rechörive Beobachitung int die von Trump p. Derselhe hat aus pleuritischem Eiter den I'sendobacillis gezüchtet. Diese Bacillen waren so ungiftig. dass 5 cem bei einem Morerschlweinchen keiue Reaction hervorriefen. Er mischte sie mit Iliphltheritrtoxin. spritzte sie wieder ein. züchteto sie wieder, und so grtlang (s ihm. durch mehıfaches Umzüchten diese Psendobacillen in höehst giftige ımr.uwandeln. die ganz das Bild der experimentellen Diphtherie hervorriefen. Uiese Untersuchung stammt aus der Escherich'schen Klinik. in dor man sich seln eingehend mit dem Studium des Diphtherichacillus befasst lat: nıan kann wohl kilum an der Thatsache zweifeln. selbst wenn sie noch vereinzelt dasteht.

Zudem hat sich gezeigt. dass der Pseudodiphtheriebacillus gar nicht so harmlos ist. wie man anfänglich glaubte. Die meisten Versuchsthiere. wenn sie auch anfangs keine Reaction zeigen. gehen bei Anwendung vor grösseren Injectionsmengen nach füf bis sechs Wochen ohne erkennbare Ursache eill.

Wirl die Untersuchung Trumpps bestitigt. so ist meiner Ansicht nach der volle Beweis erbracht. dass beide Mikrooromisinen ineinander übergehen. dass es tiberhaupt nur ein Mikroorganismus ist.

Nehmen wir aber an. dieser Beweis stelt noch aus. so sind wir be-

\section{Ueber die Pathogenität der Loeffler schen Diphtheriebacillen.}

\section{Von Dr. Fritz Sehanz, Augenarzt in Dresden.}

In der Lumge diabetischer Tuberkuloser ${ }^{3}$ ), in der Lunge nicht diabetischer Tuberkulöser ${ }^{4}$ ). bei Noma ${ }^{5}$ ). im Empjemeiter. bei Schankergeschwïren. bei Oznena. in Vaccinepusteln. und wer zälltt alle die Affectionen. bei denen heute schon das Vorkommen von Isoeffler'schen Diplitheriebacillen und diesen ganz ähnlichen ungiftigen Bacillen beschrieben worden ist. Fast alle Untersucher finden zwar zwischen den echten Diphtheriebacillen und den Pseudobacillen Unterschiede. es ist nur dabei auffällig. dass fast jeder andere Unterschiede constatirt und dass diese Unterschiede neist so unbedeutend sind. dass sie schon von vornherein nicht als durchgreifend erscheinen können. Dass der echte Diphtheriebacillus nıorphologisch und culturell mannielifach variirt. ist rou verschiedenen Seiten festgestellt und auerkannt.

Die für den Pseudobacillus als charakteristisch angegebenen Unterschiede liegen fast alle im Bereich der Variationen. dio der echte Bacillus zeigt. und rnan wird Pseudobacillen. die keine stirkeren Variationen zeigen als die echte'll. nicht als eine besondere Art aufstellen kömen. Loeffler sellsst soll. wie mir mündlich berichtet wurde - ein gedruckter Bericht ist noch nicht erschienen ${ }^{6}$ ) - anf dem lyggienischen Congress in Madrid

1) Conf. Kadije, Ueber die Bhlutgefässe des menschlichen Riickenmarkes 1889

2) Die Untersuchung des Rilckenmarkes meines Falles ist noch nicht beendet. und ich behalte mir vor. nber ein bemerkenswerthes Resultat eventuell spïter Mittheilung zu machen.

3) Nünclener medicinische Wochenschrift 1897. No. 52.

4) Berliner klinische Wochensehrift 1898. No. 14.

5) Deutsche medicinische Wochenschrift 1898. No. 15.

6) Mittlerweile hat die Berlines klinische Wochenschrift 1898. S. 367 folgenden Bericht gebracht: Loeffler erklärt. dass man als Diphtheriebacillus nur denjonigen Mikroorganismus bezeichnen kann. der das specifische Diphtheriegift zul erzengen inıstande ist. weleher weiterhin in specifischer Beziehung zum Behring schen Diphtherieantitoxin steht. Die morphologischen Kriterien. auch die in nenerer Zeit von Neisser angegebene Körnchenfïrbung hat keine specifische Bodeutung fiur die Erkenung des echten Diphtheriebacillus. Kraus, Spronk. Dauler vertreten diese Anschaunngen auf Grund ihrer Untersuchungen, welche widerspruchslos anerkannt sind. rechtigt. von giftigen und ungiftigen Loeffler schen Bacillen zu sprechen. und haben nur fïr weitere Betraclitungen mit den zwci Moglichkeiten zu rechnen: 1) beide sind identisch. 2) beide sind verschicden. Loeffler und die meisten Autoren nelumen den dualistischen Standpunkt ein, sic halten sie für verschieden. Und nur von diesem Standpunkte aus kann die jetzt geltende Thenrie über die Aetiologic der Diphtherie aufrecht gehalten werden. Stellt man sich auf den mitarischen Standpunkt. (1klärt man beide für identisch. so werden die jetzt herrschenden Al!schaumgen eine wesentliche Modification erfahren müssen. Meiner Ansicht nach ist es nicht zulässio, un einer Theorie willen auf einer Dentmul zu bestehen. wo eine andere nicht minder wahl scheinlich. ja durch Thatsachen wesentlich gestützt wird. Mögen weitere Untersuchungen uns helehren. zur Zeit ist man jedenfalls berechlitigt. auch die andere Möglichkcit zu erwägen, und es dürfte deshalb auch gerechtfertigt sein. der lierrschenden Anschauung gegeniiber auch den entgegenlogesetzten Standpunkt zu vertreten.

Der Erreger der Diphtherie kann nnmöglich eiu Mikroorganisums sein. der so verbreitet ist. dass (2r sich in der Mundlöhle anf der. Bindehaut jedes zweiten Menschen findct. Einem solchen Mikroolyanismus könnte man hüchstens eine zwcito Rolle in Diphtherienrocess einräumen. Schon in meinem Vortrag 1894 habe ich auf dicse Mogrlichkeit hingewiesell. Wir künuten anmehmen. dass dieser Bacillus, der sich auf allen der Luft ausgesetzten Schleinliäıten hänfig findet. sich bei Entzündungen derselben rasch vernelnt, in den Ijiphtheriemembranen erlangt er ausserdem noch die Fïliglkeit. einen starken Giftstoff zu produciren. Dieser Giftstoff ist es. der den Organismus schädigt. die Krankheit zu einer gef:̈hrlichen macht. In vielcul Arbeiton anch von Forschern. die entschieden auf den Standpunkt der Dualisten stehen. sielt man jetzt den Versuch machen, neben dem Loefflerschen Bacillus noch einell zweiten Fictor anfzufinden. der den Diphtherieprocess beeinflusst. Vor allen sucht man der Symbiose des Diphtheriebacillus mit anderen Bacterien eine besondere Bedentung cinzuräumen. Roux und Yersin wollen, wie oben schon erwälnt. durch gleiclizeitige Injection von Streptococcen die Virulenz der Diphtheriebacillen gesteigert haben. Ihre Untersuchungen finden unter anderem. Wenn anch in beschränlitem Maasse. Bestätioung durch dite Untersuchung Hilbert's. bei dessen Versuchen die Virulenzsteigerung sich immer in mässigen Grenzen lielt. Man meint. dass die gleichzeitig

1) Jahresbericht der Gesellschaft für Natur- ınd Heilkunde zu Dresden 1895. S. 34, und Berliner klinische Wochensulnift 1896, No. 12 
vorhandenen Streptococcen die Giftigkeit steigeru, den Process zu einem gefährlichen machen.

Wenn diese Dentung zulïssig ist. so dürfte auch die andere nichtganz in das Bereich des Unmöglichen gehören, dass der Diphtherieprocess durch eine uns noch unbekannte Ursache ansgelöst. erst durch das Znsammentreffen oder später erfolgende IJinzutreten des L oeffler'schen Bacillus zu einer gefährlichen Krankheit wird.

Gegen die Anschauung. dass die Symbiose mit Streptococcen allein eine Virnlenzsteigerung bewilkt, kommen mir Bedenken. und zwal durch meine Untersuclumgen über die Xerose. Bei der Xerose. vor allem bei der Xerose mit Keratomalacie, finden sich, und das ist von vielen Autoren bestätigt, sehr liäufig niasseuhaft Streptococcen, und doch sind die L oeffler'schen Bacillen dabei stets ungiftig. Die L oeffler'schen Bacillen werden also in diesen Fällen nicht von den Streptococcen in ihrer Virulenz beeinflusst. Froilich hat meine Ausicht, dass die sogenanuten Xerosebacillen nichts anderes sind, als ungiftige Loeffler sche Bacillen, unehrfach Widerspruch erfahren.

Zunächst war es Axenfeld'), der nieinte, zwischen dem Xerosebacillus und den I, oeffler-Hoffmanu'schen Pseudodiphtheriebacillen Unterschiede aufteclit erhalten zll können. Seine Beweisführung ist hinfällig geworden. da alle die Merkmale, die nıan fül den Pseudodiphtheriebacillus als charakteristisch bezeichnete. gefallen sind. Einen Pseudodiphtheriebacillus nach Hoftmann-L o effler giebt es nicht mehr. Nenerdings lat E. Franke ${ }^{2}$ ) die Unterschiede zwischen den Xerose-, Diphtherieund Psendodipltheriebacillus festzıstellen versucht. Durch ihn wird die Frage noch weiter complicirt. Er unterscheidet zwischen Pseudodiphtheriebacillus des Racheus und Pseudodiphthericbacillus des Auges. Beide sollen verschieden sein, und der Xerosebacillus soll sich von den Psendobacillus des Anges sicher unterscheiden lassen, dem Psendodiphtheriebacillus des Racheus aber selur nahe stehen. vielleicht gar mit ihm identisch sein.

Vergleicht man die Untersuchıng dieser beilen Autoren mit einander. so zeigt sich darin wieder. wie wechselnd die Befunde sind. Franke find, lass anf Agar seine Xerosebacillen kräftig wuchsen, wälrend die Pseudodiphtheriebacillen des Anges ein spärliches Waclisthum zeigten. Axenfeld fand das Gegentheil. seine Xerosebacillen zeigten anf Agar kümmerliches, sehr langsames Wachsthum. während seine Pseudodiphtheriebacillen schnell und üppiger wuchsen. Auf Serum bildet bei Franke der Xerosebacillus ïppigere Auf lagernngen als der Pseudodiphtheriebacillus des Auges. bei Axenfeld zeigt ungekehrt der Pseudodiphtheriebacillus cin vicl reichlicheres und feuchteres Wachstlum als der Xerosebacillus.

Diese widersprechenden Befunde erklären sich nur daraus, dass die Xerosebacillen ebenso stark variiren wie die echten Loeffler schen Stäbchen. In wie weiten Grenzen diese variiren konnen, zeigt erst neuerdings wieder die Arbeit vou Sch ütz ${ }^{3}$. Durch den Nachweis. dass der Xerosehacillus ebenso variabel ist wie die ecliten Loolfler'schen Stäbchen, ist cine nene Stiitze für die Behauptung. gewounen class beide identisch seien.

Dieser bei Xeroso sich findendo Bacillus wird nun, wie vielfache Untersuchungen gezeigt liaben. anch da, wo cr sich mit massenhaften Streptococcen in Auge findet, nie stärker virulent. Wir hätten hier also einen Loeffler schen Bacillıs, der mit Sicherheit durch Symbiose mit Streptocoscen nicht giftig wird. Sollte sich zeigen, dass die echten Diphtheriehacillen durch Symbiose mit Streptococcen eine Steigerung ihrer Virulen'z annelnmen, so hätten wir vielleicht hierin ein Mittel, beide Arten zu tremen. Freilich, nach den vielen vergeblichen Versuchen ist die Wahrscheinlichlieit. so zum Ziele zu gelangen, auch leine grosse.

Hilbert gielt an, dass sich bei seinen Versuchen die Virulenzsteigerung stets in bescheidenen Grenzen hiclt. Eine geringe Virulenzsteigerung festzustellen, dürfte seine grossen Schwierigkeiten haben, denn, wann der Tod des Versnchstllieres eintritt. hängt nicht allein von der Giftdose. sondern nuch von der Beschaffenheit des, Versuchsthieres ab. Der einige Stunden eher oder später erfolgendle Tod wird nicht ausschlliesslich auf die Giftigkeit der verwandten Cultur bezogen werden dürferl. Darum diurfte es anch unmöglich sein, bescheidene Virulenzschwankungen festzustellen. Beweisend können solche Versuche nur sein, wenn dentliche Irifferenzen festgrestellt werden, wie sie Roux und Yersiu hoobabchtet haben wollen. Mir will es scheinen. als ob die Versuche Hilbert's eher gegen als für die Beweislraft cler Roux- und Yersinschen Experimente sprechen.

Zun Scliluss möchte jchl hier zwei Fälle ans der Litteratur hervorleben, die vielleicht jetzt eine weitere Benchtung verdienen. In Jallre 1892*) berichtete ich bei Gelegenheit einer Untersuchung auf Xerosebacillen, dass ich bei einem Staroperirten wenige Tage nach der Operation mehrmals ans einer zwischen den schlecht adaptirten Wundrändern liegenden Schleimflocke diesen Bacillus gezïchtet habe. Danals war das

1) Berliner klinische Wochensclurift 1898, No. 9.

2) Münchener medicinische Wochenschrift 1898 , No. 16

3) Zur Frage der Mischinfection bei Lungentuberkulose (Dipltherieund diphtherieähnliche Bacillen in tuberkulösen Imngen). Berliner klinische Wochenschrift 1898, Seite 335.

t) Archiv für Augenheilkunde Bd. XXV, S. 110.
Vorkommen von Loeffler'schen Bacillen in Conjunctivalsack noch nicht bekannt. der Bacillıs wurde als Xerosebacillus gedeutet und anch nicht auf seine Giftigkeit geprüft. Anf der Versannnlung der Oplithalmologen 1896 berichtete v. Hippel sen. ${ }^{1}$ ). dass er aus dem Conjunctivalsecret eines Staroperirten in der ersten Woche. olıe dass stärkere Entzündung bestand, den virnlenten Diphtheriebacillus geziichtet liabe. Professor C. Fraenkel hat den Befund nachgeprüft und bestätigt.

In beiden Fällen fanden sich Loeffler sche Bacillen in Starwunden au menschlichen Augen, ohne dass sich Diphltherite entwickelte. Dieso Fülle, wären sie einwandsfrei, würden mehr beweisen, als alle Thierexperimente. Aber in meinem Falle fehlt die Prüfung der Virulenz, es bleibt der Einwand. dass es doch kein echter Lo effle r'scher Jacillus war, dass der Xerosebacillus eben doch noch etwas von diesenı Verschiedenes ist. Bei denı v. Hippel'schen Fall ist die Virulenz zweiftllos festgestellt, aber der Fall ist bisher vereinzelt. und man liat den Einwand. dass diesem Patienten ein doppeltes Gluick beschieden war. dass er. der sein Angenlicht wiedererlangt hat, auch tiber eine reichliche Menge von Sclıtzkörpern verfügte, die ihn vor den Gefahren einer Iiphtherieinfection bewahrten Sind beide Fïlle anch nicht vollbewcisend. so zeigen sie uns doch einen Weg. wie wir zu Resultaten gelangen können, die nehr beweisen, als die jetzt üblichen Thierexperimente. 